\title{
7 \\ VINCULACIONES DEL ESTADO PROVINCIAL DE SANTA FE PARA LA PROMOCIÓN DEL DESARROLLO ECONÓMICO (1991-2015). UNA APROXIMACIÓN DESDE LA IDEA DE CAPACIDADES ESTATALES
}

\author{
Mauricio Moltó (•) \\ Universidad Nacional del Litoral
}

\begin{abstract}
RESUMEN
El objetivo del trabajo es describir la red de vínculos construidos desde el Estado de la Provincia de Santa Fe y establecido con distinto tipo de instituciones a los fines de coadyuvar el desarrollo económico. Se consideró el período 1991-2015, haciendo foco, principalmente, en las diferencias entre la década de los 90 y la postconvertibilidad. Conceptualmente, el trabajo se enfocó de acuerdo a las nociones de capacidades estatales y desarrollo. Metodológicamente, se trabajó con las leyes sancionadas por la Legislatura provincial entre 1991 y 2015 relacionadas a cuestiones de desarrollo económico que establecen vinculaciones con instituciones y organizaciones de distinto orden. Los documentos fueron analizados con el software Atlas.ti.
\end{abstract}

\section{PALABRAS CLAVE:}

capacidades estatales; estado subnacional; desarrollo económico

(•)E-mail: mauriciomolto@gmail.com

\section{KEY WORDS:}

state capabilities; subnational state; economic development.

RECEPCIÓN: 16/02/16

ACEPTACIÓN FINAL: 05/05/17 